\title{
Collecting finely-dispersed particles from the gas flow in a centrifugal separator with coaxially arranged pipes
}

\author{
Vadim E. Zinurov ${ }^{1}$, Oksana S. Dmitrieva ${ }^{2, *}$, and Oksana S. Popkova ${ }^{1}$ \\ ${ }^{1}$ Kazan State Power Engineering University, 420066 Krasnoselskaya str. 51, Kazan, Russia \\ ${ }^{2}$ Kazan National Research Technological University, 420015 Karl Marx str. 68, Kazan, Russia
}

\begin{abstract}
The article deals with the problem of increasing the efficiency of dedusting the gas flow from the finely dispersed particles smaller than $10 \mu \mathrm{m}$. In order to solve this problem, a design of centrifugal separator with coaxially arranged pipes is proposed. The described principle of operation includes the large values of centrifugal forces, which take place inside the device when the flow is swirled, and these forces throw the finely dispersed particles to the walls of device. This scientific paper shows a numerical simulation of gas flow dedusting process by means of ANSYS Fluent software package. The efficiency of dedusting the gas from the finely dispersed particles of up to $10 \mu \mathrm{m}$ in the device is on average within the range of $53.8-76.7 \%$. The exponential function, describing the changes in the pressure loss from the input gas rate, is obtained. In the course of studies, it was found that the pressure loss in the device is not more than $800 \mathrm{~Pa}$ at the input gas rate from 3 to $19 \mathrm{~m} / \mathrm{s}$.
\end{abstract}

\section{Introduction}

Improving the quality of dedusting the gas flows from the finely dispersed dust particles is an urgent task for the production enterprises, which have sources of dust emissions [1]. For example, the main sources of dust emissions in the metallurgical industry are the activities related to the unloading of furnace burden into the bunker, unloading into the mobile weighbridge for wagons; a large number of particles of unburned fuel and ash dispersion, in the electricity-producing industry, is contained in the fume gases; dust, in the food industry, is emitted during the production of various food products; dusty gas flows are formed in the construction industry during air transportation of different materials etc. [2-7].

The stricter standards for dedusting the gas flows are caused by the increased requirements for maximum permissible emissions into the environment and internal sanitary norms. Also, many enterprises revised the ways of handling with collected dust. It can be re-used in the technological processes after preliminary treatment, for example, dry collected dust from the fume gases is re-fed to the combustion chamber furnaces at power and metallurgical facilities. In some cases, there is an economic profitability to use the

\footnotetext{
Corresponding author: ja_deva@mail.ru
} 
collected dust as a material for the production of other products. For example, the collected ash and slag are used for concrete mortars. Therefore, effective collection of dust particles from gases is of a great demand from environmental and economic point of view [8].

As of today, a large number of various devices with high efficiency of dedusting the gas flows were developed, for example, various modifications of inertial dust collectors, such as dust-collecting chambers, cyclones, etc. [9-18]. Easy operation, high reliability and ability to operate at high temperatures and pressures are important advantages of these devices. However, one of the main drawbacks is the low efficiency of dedusting the gas flows from the particles smaller than $10 \mu \mathrm{m}$ [19]. In order to eliminate this drawback, the technological (process) line for the gas flow purification is equipped with additional devices, for example, a wet purification device or a bag filter shall be installed after an inertial dust collector. However, high capital and operating costs, increased maintenance requirements for these devices, etc. are the limiting factors for the use of them. Therefore, the development of new technological designs of devices for dedusting the gas flows from the particles smaller than $10 \mu \mathrm{m}$ with high efficiency and low pressure loss inside them is an urgent and relevant task [20].

\section{Device description}

The authors developed a design of centrifugal separator with coaxially arranged pipes (Fig. 1).

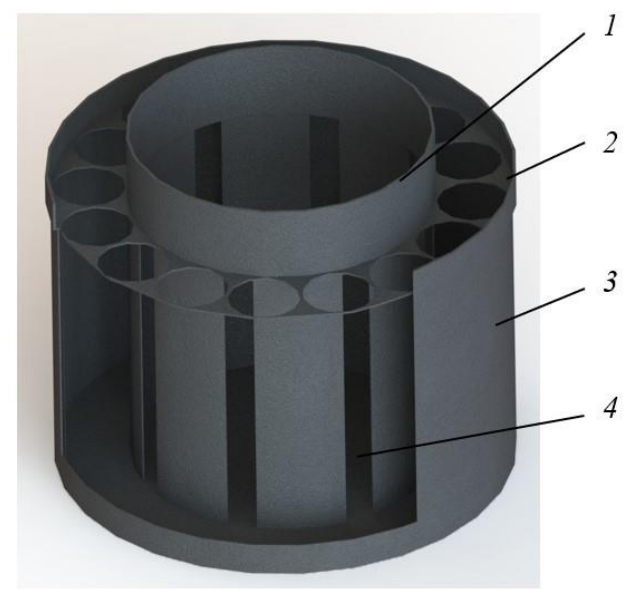

Fig. 1. Three-dimensional model of centrifugal separator with coaxially arranged pipes: 1 -inlet pipe, 2 - ring with holes, 3 - casing of centrifugal separator, 4 - slots.

This device is designed for dedusting the gas flows from the particles smaller than 10 $\mu \mathrm{m}$. It is proposed to use a centrifugal separator as the second purification stage for dedusting the gases from the finely dispersed particles after inertial dust collectors, such as, cyclones. The developed design consists of cylindrical body 3 , inside which there is an inlet pipe 1 , intended for feeding the dusty flow into the device and its uniform distribution in an axisymmetric direction through the rectangular slots 4 and rings with holes 2 for the output of purified gas flow. The principle of device operation is the following: the dusty gas flow enters the centrifugal separator through the inlet pipe 1 , after that the flow is randomly divided into equal volumes and changes its direction towards the closest slots 4 . Further, each gas jet, moving through the slot, is divided into two flows, which are swirled, due to the design of separator, namely the geometric arrangement of slots 4 and the exit holes, 
executed in the form of rings with holes 2. When swirls are formed, the centrifugal forces arise, throwing the particles from the structured flow to the "dead" zones, located between the pipes. When getting there, the particles settle to the bottom of centrifugal separator or adhere to the surfaces of inlet pipe 1 or the inner wall of housing 3 . It should be noted that for the actual design of device, instead of separator bottom, the dust bag shall be used. After that, the purified gas flow leaves the centrifugal separator through the exit holes, which are used as rings with holes 2 .

The purpose of this paper is a numerical simulation of gas flow dedusting process in a centrifugal separator with coaxially arranged pipes (Fig. 1). The numerical simulations were conducted by means of ANSYS Fluent software package. In order to conduct the studies, a three-dimensional model of centrifugal separator was created, shown in Fig. 1. In the process of creation of three-dimensional model, the following geometrical dimensions were taken: the height of device $-125 \mathrm{~mm}$, the diameter of inlet pipe $-100 \mathrm{~mm}$, the diameter of ring $-24 \mathrm{~mm}$, the width and height of slot $-10 \mathrm{~mm}$ and $97 \mathrm{~mm}$, respectively, the diameter of device $-150 \mathrm{~mm}$. The number of rings with holes and slots was 16 and 8 , respectively. In the course of studies, two variants of gas flow dedusting process were considered: adhesion of particles to the surfaces when they are in direct contact, and reflection of particles from the walls. Consideration and analysis of these two variants are extremely important. On the one hand, the finely dispersed particles adhere to almost all surfaces due to electrostatic and intermolecular forces, Brownian motion, and other forces. On the other hand, the finely dispersed particles can be re-drawn into the flow structure from the "dead" zones due to high values of centrifugal forces in the device.

In the course of studies the gas flow rate was set at the inlet of device, which varied from 3 to $19 \mathrm{~m} / \mathrm{s}$. At the outlet of device, the ambient pressure was set as equal to 101325 $\mathrm{Pa}$. The number of particles $n$ in the gas flow was set as equal to 1000 , and the density of finely dispersed particles $1075 \mathrm{~kg} / \mathrm{m}^{3}$. In order to determine the dependencies, the diameter of particles $a$ was changed from 1 to $10 \mu \mathrm{m}$.

The operation efficiency of centrifugal separator was determined by the following formula [21]:

$$
E=1-n_{k} / n,
$$

where $n_{k}$ - the number of particles that remain in the gas flow after dedusting process in the centrifugal separator.

\section{Results and discussion}

The results of studies are shown graphically in Figs. 2-4. The efficiency of dedusting the gas flow from the particles of up to $10 \mu \mathrm{m}$, upon a given condition of their adhesion to the surfaces of centrifugal separator, while in a direct contact of dust particles with any surface inside the device, was on average equal to $76.7 \%$ (Fig. 2).

Upon the condition of reflection of finely dispersed dust particles from the walls of separator, the efficiency of dedusting the gas flow was on average equal to $53.8 \%$ (Fig. 3). In the course of studies, it was found that the pressure loss in the centrifugal separator is not more than $800 \mathrm{~Pa}$ at the input gas flow rates from 3 to $19 \mathrm{~m} / \mathrm{s}$ (Fig. 4). The high efficiency of dedusting the gas flow from the finely dispersed particles of up to $10 \mu \mathrm{m}$ is explained by the design simplicity, which allows to create high values of centrifugal forces in the gas flow swirls between coaxially arranged pipes.

When the gas flow moves to the upper part of device, i.e. to the exit from it, each swirl, during its rotation, additionally accelerates the other two symmetrically relative to itself that increases the efficiency of dedusting the gas. When the gas flow is swirled, each swirl has a minimum number of points of contact with the surfaces of centrifugal separator, resulting in 
a minimum boundary layer, which is the reason for the low value of pressure loss in the device. The difference between the efficiency values of dedusting the gas flow upon the conditions of adhesion and reflection was about $23 \%$. As a rule, when the finely dispersed particles fly out of swirling gas flow, during its rotation and direct contact of particles with the device surfaces, they adhere to them due to their size and the large influence of intermolecular, electrostatic and other forces. However, due to the high values of centrifugal force, it is possible to overcome these forces and carry away the finely dispersed particles from the device along with the flow. Therefore, it is necessary to consider both cases when simulating the processes of dedusting the gas flows from the finely dispersed particles, which allows us to conclude that the efficiency of dedusting the gas in the device is on average within the range of $53.8-76.7 \%$.

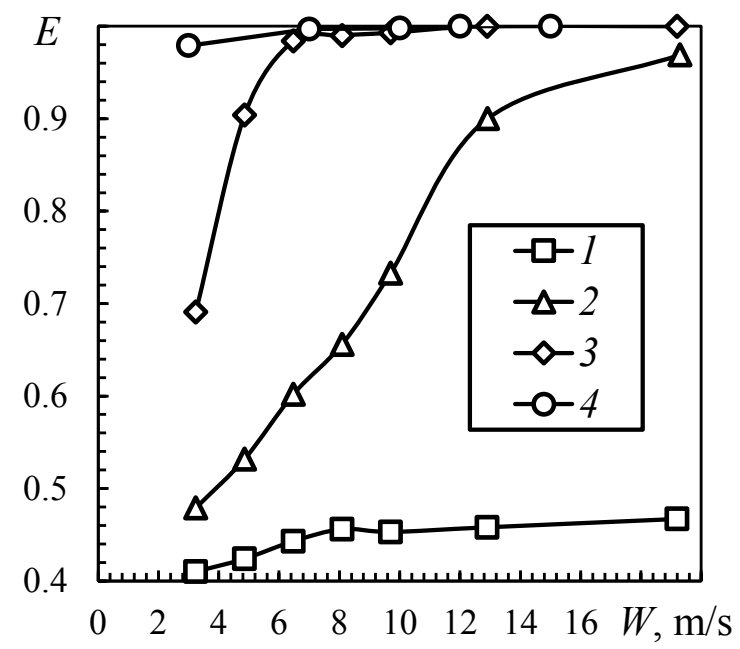

Fig. 2. The dependency of change in the efficiency of collecting the solid particles from dusty flows on the input gas rate at different sizes of particles, $\mu \mathrm{m}: 1-1,2-4,3-7,4-10$.

The efficiency of dedusting the gas flow at its input rate within the range of 3-19 $\mathrm{m} / \mathrm{s}$ from the finely dispersed particles of $1,4,7$ and $10 \mu \mathrm{m}$ was on average equal to $44.4,69.6$, 93.7 and $99.6 \%$, respectively, upon the specified condition of adhesion to the walls. It is worth noting that the efficiency of dedusting the gas flow from the particles larger than 7 $\mu \mathrm{m}$ was on average equal to $99.9 \%$ at the input gas rates equal to more than $6.5 \mathrm{~m} / \mathrm{s}$. The high degree of dedusting the gas from the particles of $4 \mu \mathrm{m}$ was achieved at a gas rate of more than $9.7 \mathrm{~m} / \mathrm{s}$, corresponding to the efficiency of at least $70 \%$. For the particles of 1 $\mu \mathrm{m}$, the efficiency of dedusting the gas flow did not exceed $50 \%$ at its rate from 3 to 19 $\mathrm{m} / \mathrm{s}$. It is worth noting that with an increase in the gas rate of more than $10 \mathrm{~m} / \mathrm{s}$, the efficiency of its dedusting by means of separator from the particles of $1 \mu \mathrm{m}$ practically did not change, moving asymptotically to a value equal to $46.1 \%$ (Fig. 2 ).

The numerical simulation was conducted under the condition of particles adhesion to the walls. The efficiency of dedusting the gas flow at its input rate within the range of 3-19 $\mathrm{m} / \mathrm{s}$ from the finely dispersed particles of $1,4,7$ and $10 \mu \mathrm{m}$ was on average equal to 15.2 , $34.4,75.4$ and $90.1 \%$, respectively, under the specified condition of reflection of particles from the walls. Similar to the simulated gas flow dedusting process, shown in Fig. 1, the highest efficiency, corresponding to the values of at least $90 \%$, was related to the particles larger than $7 \mu \mathrm{m}$ at the gas rate within the range of $6.5-19 \mathrm{~m} / \mathrm{s}$. It should be noted that for the particles of $4 \mu \mathrm{m}$, the gas dedusting efficiency equal to at least 5060 and $70 \%$ was achieved at its rate of at least 12.9, 16.1 and $19.2 \mathrm{~m} / \mathrm{s}$. The efficiency value of dedusting the 
gas from the particles of $1 \mu \mathrm{m}$, similar to the numerically simulated case, shown in Fig. 1, moved asymptotically to $15.5 \%$ at the gas rate of more than $10 \mathrm{~m} / \mathrm{s}$ (Fig. 3).

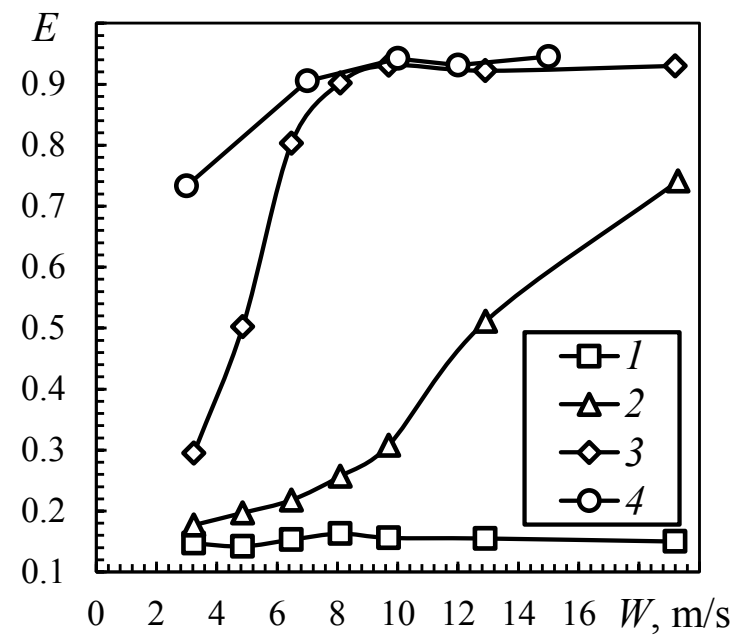

Fig. 3. The dependency of change in the efficiency of collecting the solid particles from dusty flows on the input gas rate at different sizes of particles, $\mu \mathrm{m}: 1-1,2-4,3-7,4-10$.

The numerical simulation was conducted upon the condition of particles reflection from the walls. As noted earlier, due to the ordered structure of movement, almost absence of boundary layer and the minimum number of local resistances in the centrifugal separator, the pressure loss in it was not more than $800 \mathrm{~Pa}$ at the input rate of gas flow from 3 to 19 $\mathrm{m} / \mathrm{s}$.

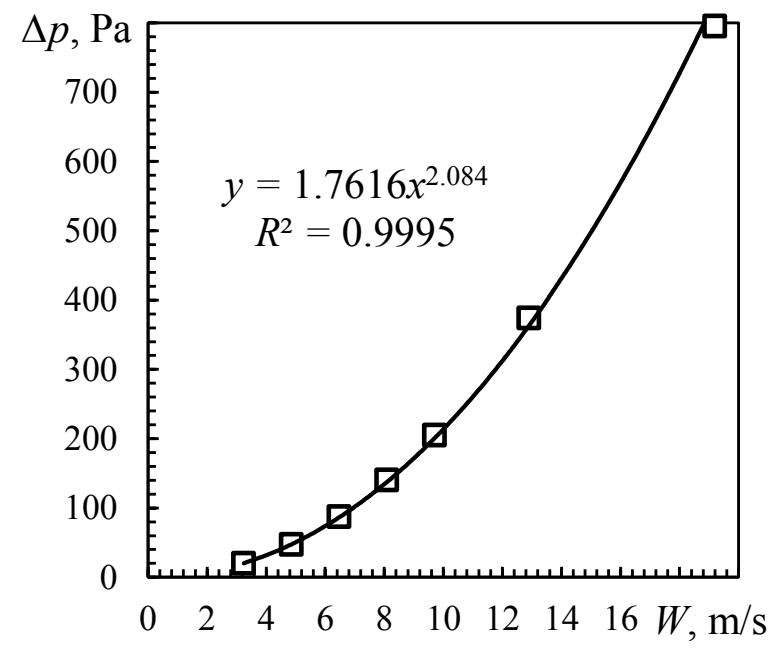

Fig. 4. The dependency of change in the pressure loss in a centrifugal separator with coaxially arranged pipes on the gas input rate.

The exponential function was determined to describe the changes in pressure loss inside the device due to the input gas rate with a high reliability value of its approximation equal to $99.9 \%$. It should be noted that a significant increase in the pressure loss in the device was achieved at the input gas rate from 10 to $19.2 \mathrm{~m} / \mathrm{s}$, the values of which varied from 205 to $795 \mathrm{~Pa}$ (Fig. 4). 


\section{Conclusion}

The conducted studies showed that the use of centrifugal separator with coaxially arranged pipes for dedusting the gases from the finely dispersed particles as the second stage of technological (process) line after inertial dust collectors, in particular, the cyclones, is advisable. When using the single centrifugal separator, the efficiency of dedusting the gas from the finely dispersed particles is of at least $50 \%$ at its input rate from 3 to $19 \mathrm{~m} / \mathrm{s}$. The use of single centrifugal separator in a process treatment line is the most rational solution mainly for dedusting the gases from the finely dispersed particles larger than $4 \mu \mathrm{m}$, since at moderate values of input gas rate of up to $10 \mathrm{~m} / \mathrm{s}$, the dedusting efficiency is of $40-70 \%$ with a pressure loss of not more than $205 \mathrm{~Pa}$ in the device. When the gas flow rate is from 10 to $19.2 \mathrm{~m} / \mathrm{s}$, the efficiency of dedusting the gas from the finely dispersed particles larger than $4 \mu \mathrm{m}$ is of $66-87 \%$ with a pressure loss in the device of not more than $800 \mathrm{~Pa}$. When dedusting the gas flow from the particles of $1 \mu \mathrm{m}$, the efficiency is on average of $15-44 \%$ at its input rate from 3 to $19 \mathrm{~m} / \mathrm{s}$. In order to intensify the dedusting of gases from the finely dispersed particles, several developed devices can be installed, connected to each other, as the second stage of process line.

The advantages of developed centrifugal separator design with coaxially arranged pipes are the high efficiency of dedusting the gas, equal to at least $50 \%$, from the finely dispersed particles of less than $10 \mu \mathrm{m}$ at low pressure loss in the device, not exceeding $800 \mathrm{~Pa}$; the wide range of operating rates from 3 to $19 \mathrm{~m} / \mathrm{s}$, the low metal consumption, the ease of manufacture, the minimum capital and operating costs.

The research was conducted with funding from the RF President's grant project No. MK-616.2020.8.

\section{References}

1. M. Fang, N. Yi, W. Di, T. Wang, Q. Wang, Int. J. Greenhouse Gas Control, 93, 102904 (2020)

2. J. Chen, Z. Zhong, Y. Xia, X. Ke, W. Xing, Chin. J. Chem. Eng., 27, pp. 1391-1402 (2019)

3. R. Singh, A. Shukla, Renewable Sustainable Energy Rev., 29, pp. 854-864 (2014)

4. F. Sh. Khafizov, V. G. Afanasenko, I. F. Khafizov, A. Sh. Khaibrakhmanov, E. V. Boev, Chem. Pet. Eng., 44, pp. 425-428 (2008)

5. N. A. Merentsov, V. A. Balashov, S. A. Bokhan, E. Nefed'eva, D. A. Tezikov, V. V. Groshev, IOP Conf. Ser.: Earth Environ. Sci., 224, 012041 (2019)

6. M. G. Ziganshin, A. M. Ziganshin, A. V. Dmitriev, Chem. Petrol. Eng., 45, pp. 230235 (2009)

7. A. B. Golovanchikov, V. A. Balashov, N. A. Merentsov, Chem. Petrol. Eng., 53, pp. 10-13 (2017)

8. S. A. Miller, P. R. Cunningham, J. T. Harvey, Resour., Conserv. Recycl., 146, pp. 416430 (2019)

9. A. V. Shvab, N. S. Evseev, Theor. Found. Chem. Eng., 49, pp. 191-199 (2015)

10. J. Wu, Y. Zhang, H. Wang, Sep. Purif. Technol., 132, pp. 541-551 (2014)

11. V. S. Shvydky, Y. G. Yaroshenko, N. A. Spirin, V. V. Lavrov, IOP Conf. Ser.: Mater. Sci. Eng., 150, 012021 (2016)

12. X. Li, T. Wei, D. Wang, H. Hu, L. Kong, W. Xiang, Chem. Eng. Sci., 151, pp. 79-92 (2016) 
13. B. K. Lee, K. R. Jung, S. H. Park, J. Aerosol Sci., 39, pp. 1079-1088 (2008)

14. U. Heck, Filtr. Sep., 53, pp. 14-16 (2016)

15. M. Kr. Prabhansu, P. C. Karmakar, P. Kr. Chatterjee, J. Environ. Chem. Eng., 3, pp. 689-702 (2015)

16. K. Reijnen, J. V. Brakel, Powder Technol., 40, pp. 81-111 (1984)

17. S. Koshkarev, A. Evtushenko, S. Pushenko, Procedia Eng., 165, pp. 1057-1069 (2016)

18. V. N. Azarov, S. A. Koshkarev, Magazine of Civil Engineering., 54, pp. 18-32 (2015)

19. A. V. Dmitriev, O. S. Dmitrieva, S. V. Dang, V. L. Nguen, Chem. Petrol. Eng., 55, pp. 329-335 (2019)

20. A. V. Dmitriev, V. E. Zinurov, O. S. Dmitrieva, E3S Web Conf., 126, 00007 (2019)

21. O. S. Dmitrieva, V. L. Nguen, N. D. Yakimov, E. G. Sheshukov, IOP Conf. Ser.: Earth and Environmental Science, 337, pp. 012057 (2019) 